\title{
Synthesize and Characterization of Hollow Boron-Nitride Nanocages
}

\author{
W. S. Zhang, ${ }^{1,2,3}$ J. G. Zheng, ${ }^{4}$ W. F. Li, ${ }^{1,2}$ D. Y. Geng, ${ }^{1,2}$ and Z. D. Zhang ${ }^{1,2}$ \\ ${ }^{1}$ Shenyang National Laboratory for Materials Science, Institute of Metal Research, Chinese Academy of Sciences, \\ Shenyang 110016, China \\ ${ }^{2}$ International Centre for Materials Physics, Chinese Academy of Sciences, Shenyang 110016, China \\ ${ }^{3}$ College of Physics \& Electronic Engineering, Taizhou University, Taizhou, Zhejiang 317000, China \\ ${ }^{4}$ Electron Probe Instrumentation Center (EPIC), Northwestern University, 2225N Campus Drive, 1156 MLSF, \\ Evanston, IL 60208-3108, USA
}

Correspondence should be addressed to W. S. Zhang, wszhangimr@hotmail.com

Received 17 May 2009; Revised 8 September 2009; Accepted 20 September 2009

Recommended by Michael Harris

The boron-nitride (BN) nanocages are synthesized by nitrogenation of amorphous boron nanoparticles at $1073 \mathrm{~K}$ under nitrogen and ammonia atmosphere. The BN nanocages exhibit a well-crystallized feature with nearly pentagonal or spherical shape, depending on their size. High-resolution transmission electron microscopy studies reveal that they are hollow nanocages. The growth mechanism of the BN nanocages is proposed.

Copyright (@ 2009 W. S. Zhang et al. This is an open access article distributed under the Creative Commons Attribution License, which permits unrestricted use, distribution, and reproduction in any medium, provided the original work is properly cited.

\section{Introduction}

Much attention has been focused on boron-nitride (BN) nanotubes and other fullerene-like nanostructures since the discovery of carbon nanotubes. BN nanotubes have been synthesized by an arc-discharge method using boride-based rods such as $\mathrm{HfB}_{2}$ and $\mathrm{ZrB}_{2}[1,2]$. The formation of hexagonal-BN nanocapsules encapsulating metal/oxides, including cobalt oxides [3], iron oxides, gold, and germanium [4], $\mathrm{Zr}$ compounds [5], silver/oxides [6], iron, and cobalt nanoparticles [7], has been reported. BN nanocages are synthesized in large amounts by nitriding $\mathrm{Fe}-\mathrm{B}$ nanoparticles under mild conditions, which shows rather promising solid-state lubricating properties [8]. A synthesis mechanism is also proposed. The effects of catalytic metals for synthesis of BN fullerene nanomaterials have also been investigated [9].

Graphite-like BN nanomaterials have layer structure similar to graphite. Nanocages belong to an important category of fullerene-like structures, to which particular attention should be addressed. This is because substances of hollow cages may show novel physical and chemical properties. For instance, nanocages may serve as nanocontainers for gas storage [10-12]. Insulating $\mathrm{BN}$ nanocages may prevent encapsulated particles from oxidization and contamination [13]. In our recent work, we encapsulated the boron nanoparticles with boron nitrides [14]. In the present work, we prepare $\mathrm{BN}$ nanocages, by means of arc-discharging in a mixture of diborane and nitrogen, followed by a subsequent annealing under a mixture of nitrogen $\left(\mathrm{N}_{2}\right)$ and ammonia $\left(\mathrm{NH}_{3}\right)$ atmospheres at $1073 \mathrm{~K}$. The structures of as-prepared nanoparticles and as-annealed $\mathrm{BN}$ nanocages are investigated by means of X-ray diffraction (XRD) and high-resolution transmission electron microscope (HRTEM).

\section{Experimental Procedures}

A mixture of amorphous boron nanoparticles and $\mathrm{Ni}$ (B) nanocapsules sheathed with boron oxide was prepared by arc-discharge in a mixture of diborane $\left(\mathrm{B}_{2} \mathrm{H}_{6}\right)$ and nitrogen $\left(\mathrm{N}_{2}\right)$ atmosphere. The anode was bulk $\mathrm{Ni}$ of $99.9 \%$ purity, while a flexible tungsten needle of $3 \mathrm{~mm}$ in diameter served as the cathode. The chamber was evacuated to $0.003 \mathrm{~Pa}$ before the introduction of gases. A mixture of $\mathrm{B}_{2} \mathrm{H}_{6}$ (purity $99.7 \%$, $2000 \mathrm{~Pa}$ ) and $\mathrm{N}_{2}$ (purity $99.7 \%, 16000 \mathrm{~Pa}$ ) was introduced into the chamber. The gas mixture serves as a reactant gas 
and a source of hydrogen plasma. A voltage in the range of 20 to $30 \mathrm{~V}$ was applied between the cathode and the anode for evaporation. The deposits on the water-cooled wall of the chamber were collected.

To synthesize BN nanocages, the nanoparticles collected from the wall were first laid down on an aluminium oxide crucible lying in an aluminium oxide tube of the furnace, isolated from air by flowing pure $\mathrm{NH}_{3}$ and $\mathrm{N}_{2}$, and then heated to $1073 \mathrm{~K}$ for 4 hours. Finally, the sample was cooled down to room temperature under pure $\mathrm{N}_{2}$.

The samples for TEM observation were prepared in two steps. First, the deposit was dispersed in ethanol in an ultrasound bath and then a drop of the suspension was transferred onto a carbon-coated TEM mesh grid and the ethanol was allowed to evaporate. The samples were examined by a JEOL 2000EX HRTEM operating at $200 \mathrm{kV}$. XRD spectra were recorded at room temperature in a Riguku $\mathrm{D} / \mathrm{max}-2500 \mathrm{pc}$ diffractrometer with $\mathrm{Cu} \mathrm{K} \alpha$ radiation and a graphite monochromator.

\section{Results and Discussion}

Diffraction peaks in the XRD spectrum of the as-prepared nanoparticles (shown as Figure 1(a)) can be indexed as $\mathrm{Ni}$ and $\mathrm{B}_{2} \mathrm{O}_{3}$ phases. We cannot find XRD peaks for boron nanoparticles. The reasons may be that (1) Boron is in amorphous state, and (2) boron nanoparticles are surrounded by $\mathrm{B}_{2} \mathrm{O}_{3}$ shells, and it was too small to be detected by XRD. Figure 1(b) shows the XRD spectrum of the nanoparticles, after annealed under $\mathrm{NH}_{3}$ and $\mathrm{N}_{2}$ and then heated to $1073 \mathrm{~K}$ for 4 hours. Besides those for $\mathrm{Ni}$, the XRD peaks that appear at about $2 \theta=26.5^{\circ}$ could be indexed as BN phase.

The typical morphology of the as-prepared nanoparticles is represented in a TEM micrograph (Figure 2). There are two kinds of nanoparticles in Figure 2, that is, boron nanoparticles and $\mathrm{Ni}$ (B) nanocapsules. Boron nanoparticles are in irregular shape and it is difficult to identify their size exactly. The typical size of the $\mathrm{Ni}(\mathrm{B})$ nanocapsules is in range of $20 \sim 200 \mathrm{~nm}$ and the discernible contrast in the TEM micrograph clearly shows that these $\mathrm{Ni}$ (B) nanocapsules are composed of a core and a shell. In our previous work [15], the phases in the shell of $\mathrm{Fe}$ (B) nanocapsules were confirmed by HRTEM to be amorphous boron oxides. It is believed that it is true also for the phases in the shell of the present $\mathrm{Ni}(\mathrm{B})$ nanocapsules.

After annealing the as-prepared nanoparticles under $\mathrm{NH}_{3}$ and $\mathrm{N}_{2}$ at $1073 \mathrm{~K}$ for 4 hours, we succeeded in synthesizing hollow $\mathrm{BN}$ nanocages. A general view of the morphology is represented in Figure 3(a). It was clearly shown that big $\mathrm{BN}$ nanocages are in a nearly pentagonal shape, accompanied with some smaller nanocages in nearly spherical shape. The size of the big nanocages in the nearly pentagonal shape is about $200 \mathrm{~nm}$, while the diameter of the nearly spherical nanocages is about $12-20$ nanometers. The formation of multilayered hollow BN nanocages by nitriding boron nanoparticles has been confirmed by enlarged $\mathrm{A}$ and $\mathrm{B}$ parts in Figures 3(b) and 3(c). Lattice fringes, originating from c planes of $h$-BN parallel to the incident electron beam,

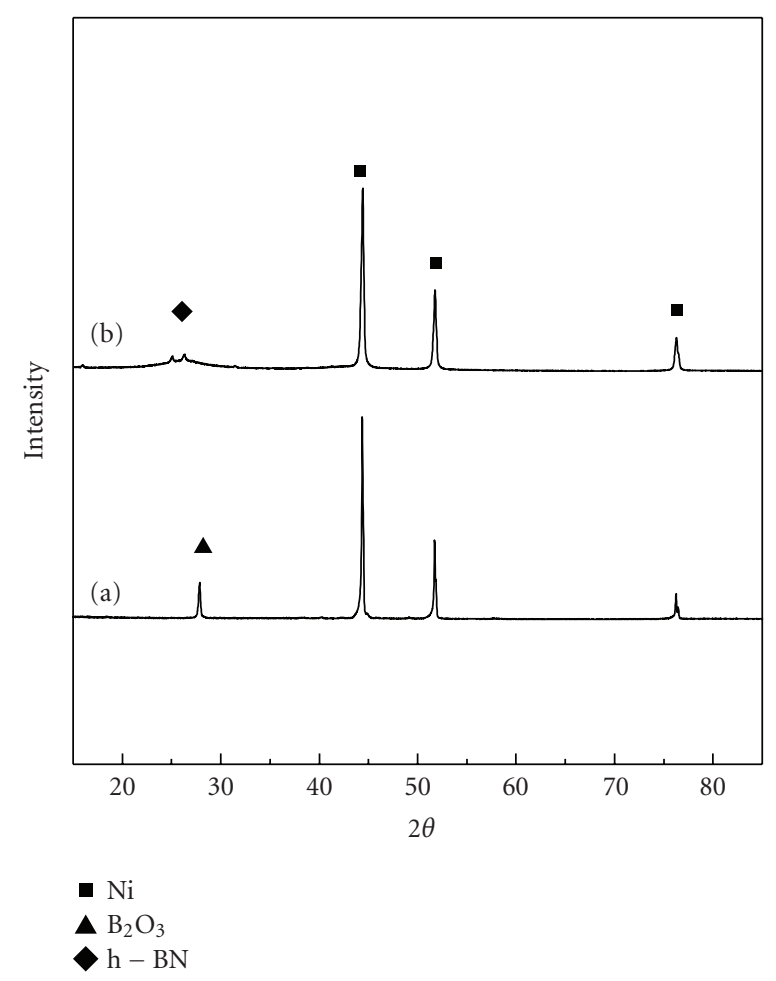

FIGURE 1: XRD spectrum of B nanoparticles and Ni (B) nanocapsules (a) as-prepared and (b) annealed under nitrogen and ammonia atmosphere.

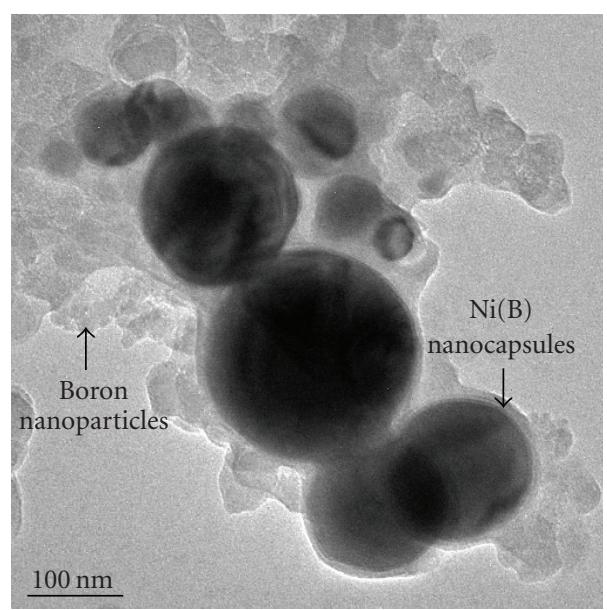

FIGURE 2: TEM images of B nanoparticles and Ni (B) nanocapsules.

are observed around the nanocages. The spacing of about $0.34 \mathrm{~nm}$ for equally separated BN layers is consistent with the interplanar distance of $0.334 \mathrm{~nm}$ in bulk hexagonal BN. The large BN nanocages have sharp inner angular, some defects as indicted by arrows, and the cages have some distortions. The contrast of the enlarged image reveals that they are really hollow nanocages (see Figures 3(b) and 3(c)).

The selected-area electron diffraction patterns from the big nanocages correspond to the (002) planes (with a spacing of $0.334 \mathrm{~nm}$ ) of hexagonal BN bulk (see inset of Figure 3(b)). 


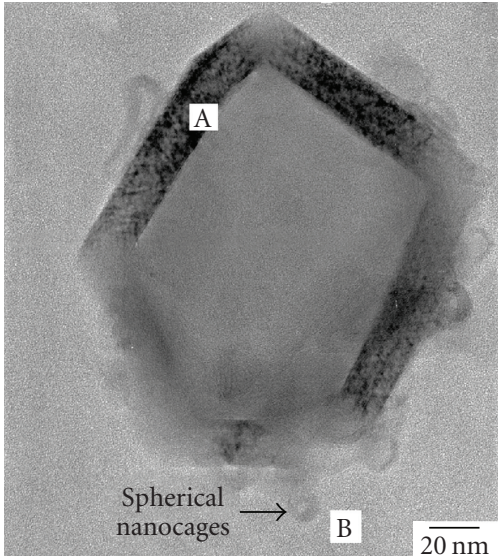

(a)

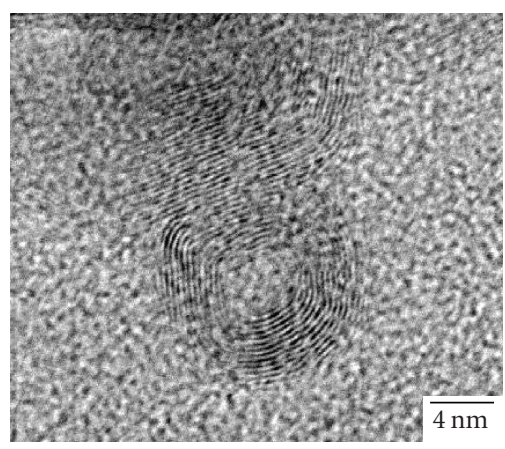

(c)

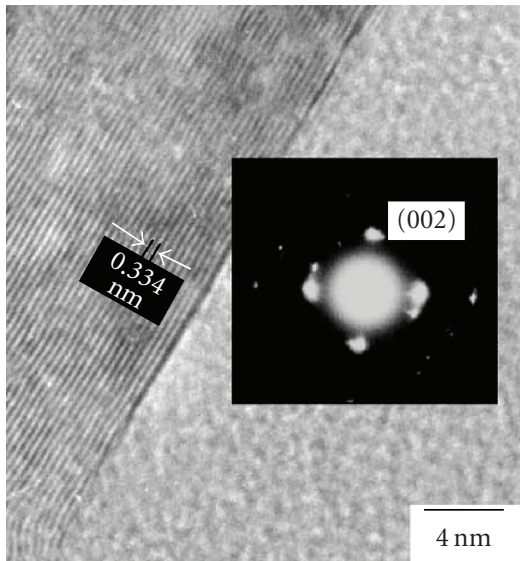

(b)

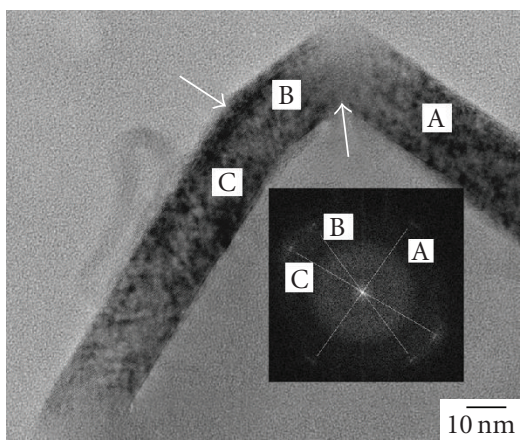

(d)

FIgURE 3: (a) Low magnification of BN nanocages and (b) HRTEM images of the BN nanocages in a nearly pentagonal shape with the corresponding selected-area electron diffraction pattern (inset (b)). HRTEM images of the BN nanocages in (c) a spherical shape and (d) a nearly pentagonal shape. Insets (d) are Fourier transform images.

The three sets of patterns correspond to the three sides of the nanocages, as proved by Fourier transform. Fourier transform reveals that these patterns come from sides A, B and $\mathrm{C}$ (Figure $3(\mathrm{~d})$ ).

Encapsulation of cobalt nanoparticles in BN nanocapsules was obtained from $\mathrm{Co}$ and boron powders in $\mathrm{H}_{2} / \mathrm{NH}_{3}$ atmosphere under heating to $1073 \mathrm{~K}$ [13]. BN encapsulated $\mathrm{Fe}_{2} \mathrm{~B}$ nanoparticles were synthesized by annealing the mechanochemically treated $\mathrm{Fe}-\mathrm{BN}$ mixtures at $1133 \mathrm{~K}$ [16]. Oku et al. prepared huge BN nanocages by acid treatment of BN encapsulated $\mathrm{Fe}$ nanocapsules [17]. BN nanocages were also synthesized by arc discharge method using $\mathrm{Ga} / \mathrm{B}$ powders [9]. It is our understanding that in this work the BN nanocages grew from the boron nanoparticles, not the $\mathrm{Ni}$ (B) nanocapsules. Usually, the traditional vapor-liquidsolid (VLS) can be used as the formation mechanism of the BN nanocages. But the VLS mechanism cannot be employed to the formation mechanism in this work, because the reaction temperature of about $1073 \mathrm{~K}$ is too low to evaporate boron. We ascribe the formation of the hollow $\mathrm{BN}$ nanocages to a solid reaction, as what have been illustrated in our previous work [14]: boron atoms at the surface of a boron nanoparticle first react with $\mathrm{N}_{2}$ gas to form a local $\mathrm{BN}$ layer, and then the layer grows along the surface of the boron nanoparticle. Compared with our previous work [14], we obtain the completely hollow BN nanocages at lower temperature. It is due to the existence of $\mathrm{NH}_{3}$, because $\mathrm{NH}_{3}$ is found to be much more effective than $\mathrm{N}_{2}$ in enhancing the sorption of nitrogen [18]. This gives a promising prospect for manufacturing different types of BN nanoparts easily.

\section{Conclusion}

Hexagonal boron-nitride (BN) nanocages were prepared by nitriding the amorphous boron nanoparticles at $1073 \mathrm{~K}$ under nitrogen and ammonia atmosphere. The big BN nanocages exhibit a well-crystallized feature with nearly pentagonal shape, while some small nanocages form with nearly spherical shape. HRTEM studies reveal that they are hollow nanocages.

\section{Acknowledgments}

The authors gratefully acknowledge the financial supports by the National Basic Research Program (no. 2010CB934603) of China, Ministry of Science and Technology China, and the National Natural Science Foundation of China under Grant 
no. 50831006, the Natural Science Foundation of Zhejiang Province under Grant no. Y407172.

\section{References}

[1] N. G. Chopra, R. J. Luyken, K. Cherrey, et al., "Boron nitride nanotubes," Science, vol. 269, no. 5226, pp. 966-967, 1995.

[2] M. Terauchi, M. Tanaka, T. Matsumoto, and Y. Saito, "Electron energy-loss spectroscopy study of the electronic structure of boron nitride nanotubes," Journal of Electron Microscopy, vol. 47, no. 4, pp. 319-324, 1998.

[3] M. Kuno, T. Oku, and K. Suganuma, "Encapsulation of cobalt oxide nanoparticles and Ar in boron nitride nanocapsules," Scripta Materialia, vol. 44, no. 8-9, pp. 1583-1586, 2001.

[4] T. Hirano, T. Oku, M. Kawaguchi, and K. Suganuma, "Formation and properties of boron nitride nanocapsules with metals and semiconductor nanoparticles," Molecular Crystals and Liquid Crystals Science and Technology. Section A, vol. 340, pp. 787-792, 2000.

[5] Y. Saito, M. Maida, and T. Matsumoto, "Structures of boron nitride nanotubes with single-layer and multilayers produced by arc discharge," Japanese Journal of Applied Physics, Part 1, vol. 38, no. 1A, pp. 159-163, 1999.

[6] T. Oku, T. Kusunose, T. Hirata, et al., "Formation and structure of $\mathrm{Ag}, \mathrm{Ge}$ and $\mathrm{SiC}$ nanoparticles encapsulated in boron nitride and carbon nanocapsules," Diamond and Related Materials, vol. 9, no. 3, pp. 911-915, 2000.

[7] N. Koi, T. Oku, I. Narita, and K. Suganuma, "Synthesis of huge boron nitride cages," Diamond and Related Materials, vol. 14, no. 3-7, pp. 1190-1192, 2005.

[8] Y. Pan, K. Huo, Y. Hu, et al., "Boron nitride nanocages synthesized by a moderate thermochemical approach," Small, vol. 1, no. 12, pp. 1199-1203, 2005.

[9] I. Narita and T. Oku, "Effects of catalytic metals for synthesis of BN fullerene nanomaterials," Diamond and Related Materials, vol. 12, no. 3-7, pp. 1146-1150, 2003.

[10] M. S. Dresselhaus, K. A. Williams, and P. C. Eklund, "Hydrogen adsorption in carbon materials," MRS Bulletin, vol. 24, no. 11, pp. 45-50, 1999.

[11] S. Trasobares, O. Stéphan, C. Colliex, et al., "Electron beam puncturing of carbon nanotube containers for release of stored $\mathrm{N}_{2}$ gas," European Physical Journal B, vol. 22, no. 1, pp. 117-122, 2001.

[12] M. Terrones, R. Kamalakaran, T. Seeger, and M. Rühle, "Novel nanoscale gas containers: encapsulation of $\mathrm{N}_{2}$ in $\mathrm{CN}_{x}$ nanotubes," Chemical Communications, no. 23, pp. 23352336, 2000.

[13] H. Kitahara, T. Oku, T. Hirano, and K. Suganuma, "Synthesis and characterization of cobalt nanoparticles encapsulated in boron nitride nanocages," Diamond and Related Materials, vol. 10, no. 3-7, pp. 1210-1213, 2001.

[14] P. Z. Si, M. Zhang, C. Y. You, et al., "Amorphous boron nanoparticles and $\mathrm{BN}$ encapsulating boron nano-peanuts prepared by arc-decomposing diborane and nitriding," Journal of Materials Science, vol. 38, no. 4, pp. 689-692, 2003.

[15] Z. D. Zhang, J. L. Yu, J. G. Zheng, et al., "Structure and magnetic properties of boron-oxide-coated $\mathrm{Fe}(\mathrm{B})$ nanocapsules prepared by arc discharge in diborane," Physical Review B, vol. 64, no. 2, Article ID 024404, 5 pages, 2001.

[16] B. Bokhonov, M. Korchagin, and Yu. Borisova, "Formation of nanosized particles encapsulated in boron nitride during lowtemperature annealing of mechanochemically treated Fe-BN mixtures," Journal of Alloys and Compounds, vol. 372, no. 1-2, pp. 141-147, 2004.
[17] T. Oku, I. Narita, and H. Tokoro, "Synthesis and magnetic property of boron nitride nanocapsules encaging iron and cobalt nanoparticles," Journal of Physics and Chemistry of Solids, vol. 67, no. 5-6, pp. 1152-1156, 2006.

[18] Z. Yang, R. Ren, X. Xie, and L. L. Shaw, "On nitrogen sorption during high energy milling of silicon powders in ammonia and nitrogen," Metallurgical and Materials Transactions A, vol. 30, no. 4, pp. 1109-1117, 1999. 

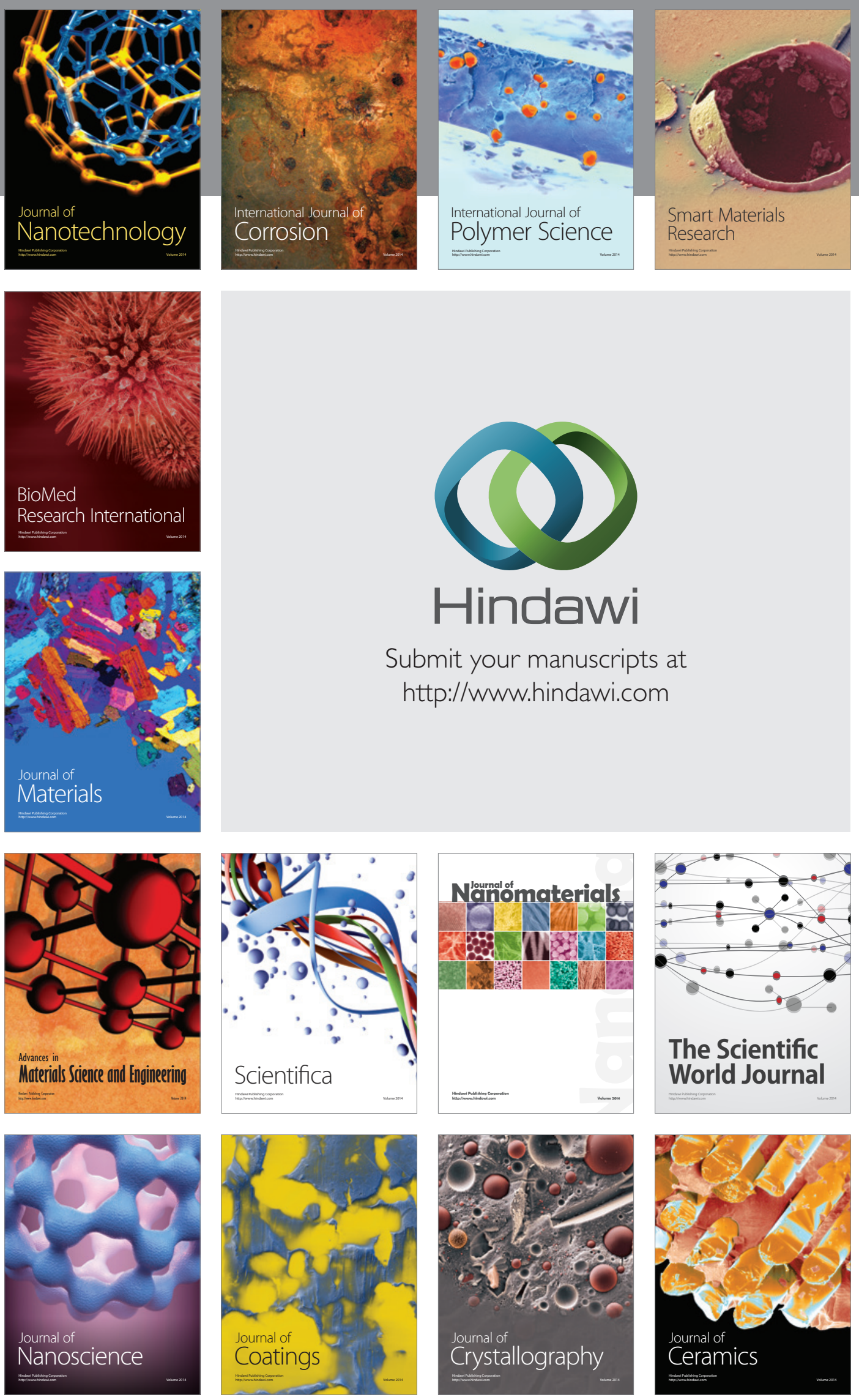

The Scientific World Journal

Submit your manuscripts at

http://www.hindawi.com

\section{World Journal}

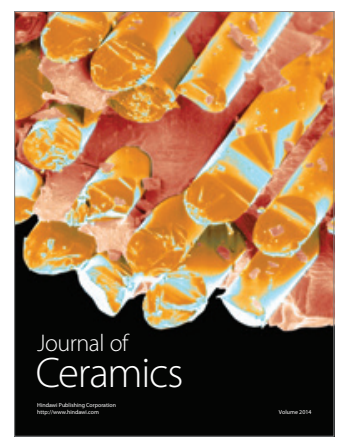

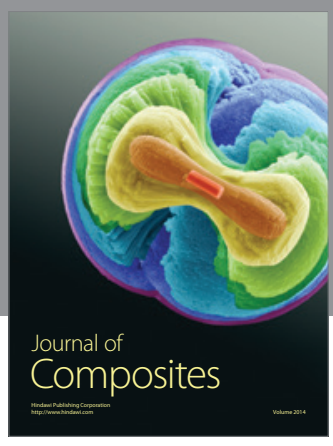
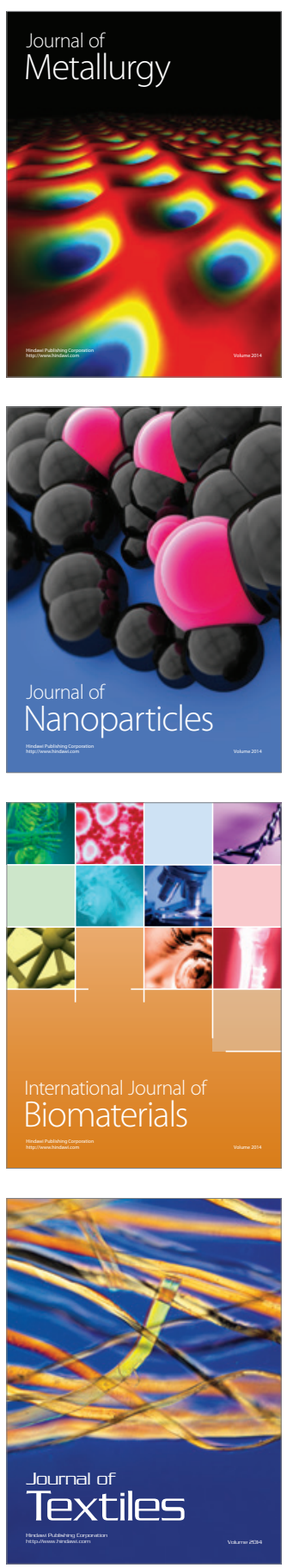